NBER WORKING PAPER SERIES

\title{
CONSERVATION: FROM VOLUNTARY RESTRAINT TO A VOLUNTARY PRICE
} PREMIUM

Matthew Kotchen

Michael Moore

Working Paper 13678

http://www.nber.org/papers/w13678

\author{
NATIONAL BUREAU OF ECONOMIC RESEARCH \\ 1050 Massachusetts Avenue \\ Cambridge, MA 02138
}

December 2007

We are grateful for helpful comments from Jim Andreoni, Jon Bakija, Bill Gentry, Joe Herriges, Felix Oberholzer-Gee, Steve Polasky, Daniel Rondeau, Steve Salant, Lucie Schmidt, Joel Slemrod, Klaas van 't Veld, two anonymous reviewers, and seminar participants at Minnesota, Tufts, Williams, Yale, the UC Energy Institute, and the NBER Workshop on Public Policy and the Environment. This research was supported in part by a grant from the United States Environmental Protection Agency. The views expressed herein are those of the author(s) and do not necessarily reflect the views of the National Bureau of Economic Research.

(C) 2007 by Matthew Kotchen and Michael Moore. All rights reserved. Short sections of text, not to exceed two paragraphs, may be quoted without explicit permission provided that full credit, including (C) notice, is given to the source. 
Conservation: From Voluntary Restraint to a Voluntary Price Premium

Matthew Kotchen and Michael Moore

NBER Working Paper No. 13678

December 2007

JEL No. H23,Q3

\begin{abstract}
This paper investigates how concern for the environment translates into predictable patterns of consumer behavior. Two types of behavior are considered. First, individuals who care about environmental quality may voluntarily restrain their consumption of goods and services that generate a negative externality. Second, individuals may choose to pay a price premium for goods and services that are more environmentally benign. A theoretical model identifies a symmetry between such voluntary restraint and a voluntary price premium that mirrors the symmetry between environmental policies based on either quantities (quotas) or prices (taxes). We test predictions of the model in an empirical study of household electricity consumption with introduction of a price-premium, green-electricity program. We find evidence of voluntary restraint and its relation to a voluntary price premium. The empirical results are consistent with the theoretical model of voluntary conservation.
\end{abstract}

\author{
Matthew Kotchen \\ Bren School of Environmental \\ Science \& Management \\ and Department of Economics \\ University of California, Santa Barbara \\ 4420 Donald Bren Hall \\ Santa Barbara, CA 93106-5131 \\ and NBER \\ kotchen@bren.ucsb.edu \\ Michael Moore \\ School of Natural Resources \& Environment \\ University of Michigan \\ Ann Arbor, MI 48109-1041 \\ micmoore@umich.edu
}




\section{Introduction}

A primary focus of environmental economics is the design of policy instruments that induce agents to internalize environmental externalities. This paper, in contrast, examines the extent to which consumers internalize their externalities voluntarily, i.e., through conservation that arises without policy interventions. With a combination of theoretical and empirical methods, we consider whether people actually exhibit voluntary conservation, to what extent, and why.

A theoretical model of consumer behavior is used to show the relationship between two potential types of voluntary conservation. The first is that consumers who care about environmental quality may demand less of a good that causes a negative externality. The second is that consumers may choose to pay a premium for goods and services that are more "environmentally friendly." We refer to these behaviors as voluntary restraint and a voluntary price premium, respectively. The model generates a series of predictions about the relationship between demand under voluntary restraint and demand with a voluntary price premium.

We test the model's predictions in an empirical study of household demand for electricity. The data come from Traverse City, Michigan, and the study period spans the date when the local public utility initiated a voluntary, premium-priced, green-electricity program to reduce air pollution emissions. ${ }^{1}$ The empirical setting - which includes panel data on monthly household electricity consumption that we combine with an original household survey-provides a unique opportunity to investigate conservation as it relates to voluntary restraint of conventional electricity and a voluntary price premium for green electricity.

Prior research has investigated various empirical aspects of voluntary restraint in the context of energy consumption. ${ }^{2}$ A few studies have analyzed whether appeals for conservation following the energy crisis of 1973 had an effect on household energy use. Peck and Doering (1976) study household demand for heating fuel and find no significant effect of a conservation campaign aimed at changing residential fuel-use patterns. Walker (1980) reviews several of these studies and provides

\footnotetext{
1 "Green" electricity is electricity generated from renewable sources of energy, including wind, solar, and geothermal energy. Most conventional electricity in the United States is generated from coal, which produces several air pollutants as by-products (e.g., $\mathrm{CO}, \mathrm{CO}_{2}, \mathrm{NO}_{\mathrm{x}}, \mathrm{SO}_{2}$, particulates, lead, and mercury).

${ }^{2}$ A substantial literature investigates utility-sponsored voluntary programs for energy conservation, such as timeof-use rates and home energy audits. The primary reason to enroll in such programs is to reduce energy expenditures. Here we consider conservation that is motivated only for non-pecuniary reasons.
} 
evidence that the energy crisis stimulated conservation beyond that which can be explained by changes in price or income. Estimates of the conservation effect range from 4 percent for electricity to 10 percent for natural gas. Lee (1981) finds a similar result, with estimates ranging from 1 to 4 percent, for conservation of electricity due to a public relations campaign in the mid-1970s. More recently, Reiss and White (2005) investigate the effect of public appeals for conservation related to the California energy crisis in 2000-2001. They find that, absent any economic incentives to do so, households reduced their electricity consumption by 6 percent for extended durations following a conservation campaign.

There is also a recent empirical literature that investigates willingness to pay a voluntary price premium for green electricity. Many of these studies employ stated- or revealed-preference techniques to derive estimates of willingness to pay for various types of green electricity (e.g., Goett, et al., 2000; Champ and Bishop, 2001; Roe, et al., 2001). Other studies analyze factors that influence participation in a particular green-electricity program (e.g., Oberholzer-Gee, 2001; Rose, et al., 2002; Kotchen and Moore, 2007). In general, this literature finds that many households state a willingness to pay a premium for green electricity, yet actual participation depends on the program structure, household characteristics, attitudes related to the environment, and the existence of "warm-glow" motives. ${ }^{3}$

This paper makes several contributions to the literature. The theoretical model is the first to examine the relationship between voluntary restraint and a voluntary price premium. The model generates a series of new predictions that relate conservation based on quantities to conservation based on prices. Underlying the model is a symmetry between environmental policies based on either quantities (quotas) or prices (taxes). The empirical analysis is based on revealed preferences rather than stated preferences, and it takes advantage of a natural experiment in which participants in the green electricity program are compared with a control group of households on the program's waiting list. The paper also goes beyond identifying differences between participants and nonparticipants; for the first time, questions are addressed about differences in electricity consumption before and

\footnotetext{
${ }^{3} \mathrm{~A}$ "warm-glow" motive captures the idea that households may participate in a green-electricity program because it makes them feel good about "doing their part" to protect the environment. This motive is a private benefit that is distinct from any public benefit that may arise from reduced pollution (see Andreoni, 1990).
} 
after participation. ${ }^{4}$ We find evidence of voluntary restraint and its relation to a voluntary price premium. The empirical results are consistent with the theoretical model of voluntary conservation.

\section{Theoretical Model}

An extensive psychology literature on voluntary conservation is based on a model developed by Schwartz $(1970,1977)$ concerning the activation of norms for altruistic behavior. According to the model, activation of these norms depends critically on the presence of two personal beliefs: awareness that harmful consequences may come to others from inaction, and ascription of responsibility to oneself for those consequences. Individuals who possess these beliefs consider it their duty to behave altruistically; otherwise they experience a feeling of guilt from shirking their responsibility. Psychologists have used the Schwartz model to investigate conservation as it relates to electricity consumption (e.g., Black, Stern and Elworth, 1985). In this context, the necessary beliefs to motivate conservation are interpreted as awareness of pollution that arises from generating conventional electricity, and ascription of personal responsibility for some of the social costs. Because studies have repeatedly documented the importance of these beliefs for motivating household energy conservation (see Stern, 1992), the insights of the Schwartz model provide a reasonable starting point for developing an economic perspective.

Our model is based on the simplest setup capable of illustrating the relevant issues of voluntary conservation in the context of electricity consumption. We consider two types of households: conservationists and nonconservationists, where only conservationists satisfy the necessary conditions of Schwartz's norm-activation model. Assume initially that only conventional electricity is available. Households seek to maximize a utility function of the form

$$
U\left(x_{i}, y_{i} ; \gamma_{i}\right)=l\left(x_{i}\right)+f\left(y_{i}\right)-\gamma_{i} h\left(y_{i}\right),
$$

where $x_{i}$ is a numeraire consumption good, $y_{i}$ is conventional electricity, and $\gamma_{i}$ is an indicator variable such that $\gamma_{i}=1$ if household $i$ is a conservationist type, and $\gamma_{i}=0$ if household $i$ is a

\footnotetext{
${ }^{4}$ This is possible given the unique empirical setting that combines an original household survey, eight years of monthly panel data on household electricity consumption, and introduction of a green-electricity program.
} 
nonconservationist type. ${ }^{5}$ All functions map into $R_{+}^{1}$, all first derivatives are strictly positive, and the second derivatives satisfy $l^{\prime \prime} \leq 0, f^{\prime \prime}<0$, and $h^{\prime \prime} \geq 0$. This setup implies that, relative to nonconservationists, conservationists care about a negative aspect of their conventional-electricity consumption. Although there are several possibilities, we assume this is related to a pollution externality, which causes conservationists to experience guilt from consuming conventional electricity. The functional form of $h\left(y_{i}\right)$ implies that conservationists feel strictly guiltier (at a weakly increasing rate) when they consume more conventional electricity. To ensure that conservationists do consume some electricity, we assume that $f^{\prime}\left(y_{i}\right)-h^{\prime}\left(y_{i}\right)>0$ over the feasible range of $y_{i}$.

Each household is endowed with exogenous income $m$, which, for simplicity here in the theoretical model, we assume is the same for all households. Conventional electricity is available at a constant price $p .{ }^{6}$ Thus, households face the budget constraint $x_{i}+p y_{i} \leq m$. Assuming interior solutions (here and throughout), the first-order condition that implicitly defines each household's demand for conventional electricity $\hat{y}_{i}$ can be written as

$$
f^{\prime}\left(\hat{y}_{i}\right)=p l^{\prime}\left(m-p \hat{y}_{i}\right)+\gamma_{i} h^{\prime}\left(\hat{y}_{i}\right)
$$

For all households, the left hand side is the marginal benefit of consuming conventional electricity, and the right hand side is the marginal cost. Note that for conservationists the marginal cost includes guilt as well foregone consumption of the numeraire.

Letting $\hat{y}_{1}$ and $\hat{y}_{0}$ denote conventional electricity demand for conservationists and nonconservationists, respectively, it follows from (1) that $\hat{y}_{1}<\hat{y}_{0}$. This illustrates the notion of voluntary restraint: the guilt from generating pollution causes conservationists to restrain their consumption of conventional electricity. We thus have the first testable hypothesis of the model.

Proposition 1 Conservationist households will consume less conventional electricity than nonconservationist households.

Now assume green electricity becomes available. Assume further that households can participate in the green-electricity program only if they volunteer to pay a fixed premium of $\pi>0$ per unit

\footnotetext{
${ }^{5}$ Additive separability of $x_{i}$ and $y_{i}$ is only a simplifying assumption and does not affect any of our results.

${ }^{6}$ We first develop the model with a constant price per unit of electricity. We then show that the results generalize to situations with increasing block-rate schedules, which are common for electricity.
} 
of electricity consumption, for all of their electricity consumption. The price of green electricity is therefore $p_{g}=\pi+p$. Green electricity and conventional electricity are perfect substitutes in all respects other than the fact that green electricity does not generate pollution. As a result, conservationists have no reason to feel guilty if they consume green electricity; that is, $h\left(y_{i}^{g}\right)=0$ for any level of green electricity $y_{i}^{g}$. It follows that, depending on the magnitude of $\pi$, conservationist households may choose to participate in the green-electricity program in order to avoid the guilt of generating pollution through their consumption of conventional electricity.

Other factors may also prompt a household to participate in the green-electricity program. Many programs, including the one studied in this paper, offer decals for the home and car to signal participation, along with newsletters about program and participant updates. Social benefits that are unrelated to electricity consumption may therefore motivate participation; the range of possibilities includes social approval, prestige, and signaling about household income. ${ }^{7}$ Psychological benefits, which are similarly unrelated to electricity consumption, may also play a role, as participation can be associated with the "purchase of moral satisfaction" (Kahneman and Knetsch, 1992) or a feeling of "warm glow" (Andreoni, 1990). ${ }^{8}$

To capture the possibility for these social and psychological benefits, we assume that, conditional on participation, a household of either type enjoys a lump-sum benefit $k_{i} \geq 0$, which may differ among households. The lump-sum benefit implies that even nonconservationists may have a reason to participate.

The decision of whether to participate in the green-electricity program depends on a comparison of two potential levels of utility. These levels can be written as

$$
V\left(p, m ; \gamma_{i}\right) \equiv \max _{y_{i}}\left\{l\left(m-p y_{i}\right)+f\left(y_{i}\right)-\gamma_{i} h\left(y_{i}\right)\right\}
$$

\footnotetext{
${ }^{7}$ The importance of social benefits of this type has been examined in the literature on private provision of public goods. For examples see Hollander (1990), Glazer and Konrad (1996), Harbaugh (1998a, 1998b), and Rege and Telle (2004).

${ }^{8}$ In a study of contributions to a green-electricity program in Switzerland, Oberholzer-Gee (2001) finds empirical support for such psychological benefits. He concludes that "The warm-glow part of the motivation to contribute appears to be independent of the value of the public good in the sense that individuals participate in the program even if they do not believe that their use of solar energy will improve the quality of the environment. For these individuals, it is sufficient that they contribute to a cause which they believe to be important" (p. 433).
} 
and

$$
V^{g}\left(p_{g}, m ; k_{i}\right) \equiv \max _{y_{i}^{g}}\left\{l\left(m-p_{g} y_{i}^{g}\right)+f\left(y_{i}^{g}\right)+k_{i}\right\}
$$

It follows that a household will choose to participate in the green-electricity program only if $V\left(p, m ; \gamma_{i}\right) \leq V^{g}\left(p_{g}, m ; k_{i}\right) .{ }^{9}$ But what does participation imply about the existence of guilt from consumption of conventional electricity and the lump-sum benefit from participation? How will participation affect the quantity of electricity consumption? And what differences in consumption will occur between participating conservationists and nonconservationists? We now turn to these questions.

We first consider nonconservationists households. Nonconservationists clearly must enjoy a lump-sum benefit if they participate in the green-electricity program. Unless $k_{i}$ is positive, nonconservationists have no incentive to pay the price premium for green electricity, as there is no guilt to alleviate and utility is decreasing in the price of electricity. A further result follows from the fact that, for nonconservationists, $k_{i}$ affects participation, but not the marginal decision about the quantity demanded of electricity. A nonconservationist's demand for green electricity is determined by the first order condition

$$
f^{\prime}\left(\hat{y}_{i}^{g}\right)=p_{g} l^{\prime}\left(m-p_{g} \hat{y}_{i}^{g}\right)
$$

which is the same as (1) except for the difference in price. This implies that a nonconservationist's behavioral response to participation in the green-electricity program will be as if there had been an exogenous increase in the price of conventional electricity equal to the premium $\pi$.

The following proposition summarizes the results for nonconservationists.

Proposition 2 If a nonconservationist household participates in the green-electricity program, then: (a) the household must enjoy a lump-sum benefit from participation; and (b) after participating, the household's electricity consumption will decline by as much as it would if there had been an increase in the price of conventional electricity equal to the premium for green electricity.

\footnotetext{
${ }^{9}$ In another paper we motivate participation in such a green-electricity program as private provision of an impure public good (Kotchen and Moore, 2007). The model developed here can be viewed in this way as well, with green electricity producing the joint products of electricity consumption and guilt alleviation. The difference is that, with voluntary conservation, we would expect behavioral evidence of preferences even before the option for green electricity becomes available. As we will see, investigating such evidence, along with before and after comparisons of electricity demand, is the primary focus of the present paper.
} 


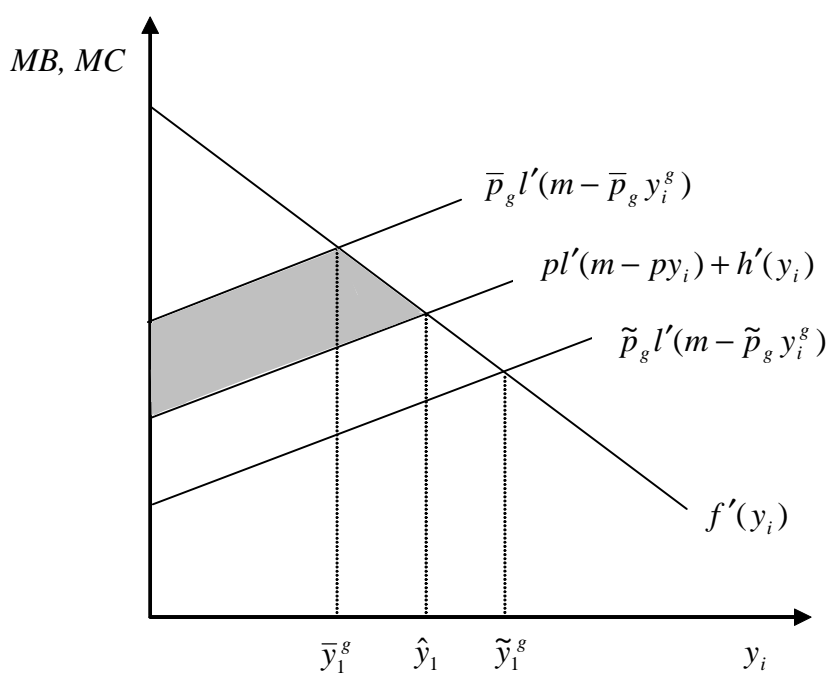

Figure 1: A conservationist's electricity consumption can increase or decrease

Now consider conservationist households. It turns out that if the price of green electricity is sufficiently high, the necessary condition for participation is similar to that for nonconservationists. To see this, assume $\pi$ is large enough so that the marginal cost curve of consuming green electricity lies above the marginal cost curve of consuming conventional electricity. Figure 1 provides an illustration with the price of green electricity $\bar{p}_{g}$. In this case, a participating conservationist will reduce electricity consumption from $\hat{y}_{1}$ to $\bar{y}_{1}^{g}$. Yet because there is a loss in surplus equal to the shaded area, participation requires an offsetting lump-sum benefit. Thus, even conservationists may require a sufficiently large lump-sum benefit in order to participate in the green-electricity program. In fact, it is straightforward to show that whenever a participating conservationist reduces electricity consumption, it must be the case that $k_{i}>0 .{ }^{10}$

More generally, conservationists differ from nonconservationists because their electricity consumption need not fall after participating in the green-electricity program, and participation does not require a lump-sum benefit. Figure 1 provides an illustration with a lower price of green electricity $\tilde{p}_{g}$ (such that $\bar{p}_{g}>\tilde{p}_{g}>p$ ). In this case, electricity consumption increases from $\hat{y}_{1}$ to $\tilde{y}_{1}^{g}$, and participation occurs even if $k_{i}=0$. Note that, in this case, households choose to pay a higher

\footnotetext{
${ }^{10}$ This follows because the assumption that $h^{\prime \prime}\left(y_{i}\right) \geq 0$ implies that if $\hat{y}_{1}^{g}<\hat{y}_{1}$, there must be a loss in surplus, as the marginal cost for conventional electricity is lower than for green electricity for all $y_{i}<\hat{y}_{1}$. Thus, to offset the loss in surplus, participation requires a sufficiently large $k_{i}>0$.
} 
price for electricity and then consume more. In order to understand this somewhat counterintuitive possibility of a increase in consumption, the important comparison is between the marginal guilt from consumption of conventional electricity at $\hat{y}_{i}$ and the increased marginal cost from the price premium of green electricity at $\hat{y}_{i}$. If the former is greater than (less than) the latter, then electricity consumption will increase (decrease). ${ }^{11}$

It is interesting to note that this relationship mirrors the symmetry between traditional environmental policies based on quantities and prices. For any good or service associated with an externality, a quota can be used to implement the efficient (or any other restrictive) quantity, or a particular Pigouvian tax can be used to accomplish the same objective. Yet, for a given quota, a sufficiently high (low) tax will implement a smaller (greater) equilibrium quantity. The relationship here is similar in that households voluntarily internalize a subjective externality and choose their quantity of voluntary restraint, which is consistent with a particular green price premium. But, conditional on participation, if the price premium is sufficiently high (low), then electricity consumption will decrease (increase).

The next proposition summarizes the results for conservationists.

Proposition 3 If a conservationist household participates in the green-electricity program, then: (a) the household's electricity consumption can increase, decrease, or remain the same, and (b) if consumption decreases, the household must enjoy a lump-sum benefit from participation.

The model generates further predictions about similarities and differences between conservationists and nonconservationists conditional on participation. Because participating conservationists have no incentive to voluntarily restrain their consumption of green electricity, they should be indistinguishable from participating nonconservationists in terms of their demand for green electricity. Moreover, because only conservationists were exhibiting voluntary restraint before participating, the model also predicts that they will reduce their consumption by less (if at all) than nonconservationists. These results are summarized in the final proposition.

Proposition 4 If both conservationists and nonconservationists participate in the green-electricity

\footnotetext{
${ }^{11}$ Considering a special case makes this idea clear. Assume utility is quasilinear in $x_{i}$ (i.e., $\left.l^{\prime}\left(x_{i}\right)=1\right)$ and marginal guilt is constant such that $h^{\prime}\left(y_{i}\right)=\mu$. In this case, it is straightforward to show that, electricity consumption will increase, decrease, or remain the same if $\pi<\mu, \pi>\mu$, or $\pi=\mu$, respectively.
} 
program, then: (a) households of both types will consume the same amount of green electricity, and (b) conservationists will reduce their electricity consumption by less (if at all) than nonconservationists.

Thus far we have assumed a constant per-unit price of electricity. Yet residential electricity pricing is often structured with an increasing block-rate schedule. It is, however, straightforward to verify that the main results hold even with a increasing block-rate. Consider a two-tiered rate structure, where the price of conventional electricity is

$$
P= \begin{cases}p & \text { for } 0 \leq y_{i} \leq y^{*} \\ p^{*} & \text { for } y_{i}>y^{*}\end{cases}
$$

where $p<p^{*}$ and $y^{*}$ is the quantity threshold between rates. ${ }^{12}$ If we continue to assume a constant premium $\pi$ for green electricity, we can modify the preceding analysis to account for the block rate. The only difference is that all marginal cost curves have a discontinuity at $y_{i}=y^{*}$; they all shift up by at least $p^{*}-p$ for $y_{i}>y^{*}$. With such a modification to the the first order conditions, it is straightforward to see that only two results change slightly: the voluntary restraint of Proposition 1 holds with a weak (rather than strict) inequality, and the second part of Proposition 4 holds weakly (rather than strictly) as well. Both of these changes occur because of the possibility that demand is exactly at the threshold between block rates.

\section{Empirical Setting and Data Collection}

We test predictions of the theoretical model in an empirical study of demand for electricity, before and after introduction of a green-electricity program in Traverse City, Michigan. The municipal utility, Traverse City Light and Power (TCL\&P), provides electricity to approximately 7,000 residential households. In 1994, TCL\&P began soliciting households to voluntarily finance a centralized wind turbine that would generate electricity and replace generation at the local coal-fired power plant. TCL\&P completed construction of the turbine and began operating the "Green Rate" pro-

\footnotetext{
${ }^{12}$ Although increasing block-rate schedules often include more than two tiers, consideration of a two-tiered schedule is sufficient to demonstrate implications for the model.
} 
gram in June $1996{ }^{13}$ To participate in the program, households are required to make a three-year commitment to purchase all of their electricity at a price premium of 1.58 cents per kilowatt-hour. This translates into an average residential premium of $\$ 8.50$ per month, or a 25 -percent increase in the average household's electricity bill. We now describe the data along with the empirical strategy of using membership in an environmental organization to classify households as either conservationists or nonconservationists.

\subsection{Survey Data}

We developed and administered a mail survey of TCL\&P residential customers. The survey was designed to collect data on socioeconomic characteristics, physical attributes of each residence, and household behaviors related to conservation. ${ }^{14}$ The survey was conducted in 2001 using the Dillman (1978) Total Design Method. A sample of 1,000 households included those that were (at the time of the survey) participants in the Green Rate program, on the waitlist, or nonparticipants. Specifically, the sample was stratified to include all 122 households that were participants, all 32 households on the waitlist, and a random sample of 846 households that were nonparticipants with utility records dating back to 1994. After accounting for undeliverable addresses, the overall response rate for the survey was 70 percent (106 participants, 27 waitlisters, and 544 nonparticipants), which is relatively high. ${ }^{15}$

The existence of a waitlist for the Green Rate program is an important feature of the data because it creates a natural experiment in which to analyze the effect of participation. Households choose whether to participate in the program, but from the very beginning the program was oversubscribed relative to the wind turbine's capacity. While households were admitted to the program on a first-come first-serve basis, the waitlist was created immediately at the outset. Subsequently, a small number of households have been removed from the waitlist to become participants only when another household withdrew from the program. With respect to participants and waitlisters,

\footnotetext{
${ }^{13}$ At the time of construction, the wind turbine was the largest operating in the United States. It produces about 800,000 kilowatt-hours of electricity per year, which can meet the needs of approximately 125 households.

${ }^{14}$ Copies of the survey instrument are available from the authors upon request.

${ }^{15}$ We use data from this survey in another study to compare participation decisions in different green-electricity programs (Kotchen and Moore, 2007). Here the analysis differs because we combine the survey data with panel data on household electricity demand. As we will show, this enables the empirical investigation of electricity consumption between different types of households, before and after participation in the green-electricity program.
} 
it is reasonable to treat actual participation as effectively random, and we take advantage of this exogeneity in the empirical analysis.

Table 1 compares descriptive statistics for the key survey variables among participants, waitlisters, and nonparticipants. As one might expect, given the discussion above, there are no significant differences between participants and waitlisters. Nonparticipants, however, differ from participants and waitlisters with respect to several variables. On average, nonparticipants have an annual household income that is about $\$ 10,000$ lower, are four years older, have two fewer years of education, and are 30 percent less likely to be a self-reported member of an environmental organization. ${ }^{16}$ In addition to the $t$-test results reported in Table 1, we conducted Mann-Whitney $U$ tests to assess whether the different groups of observations come from the same distribution. These non-parametric tests produce very similar results, with the exception of statistically insignificant differences in $k W h D a y$ in column (5) and Age in column (6).

\subsection{Utility Data}

TCL\&P began keeping electronic records of household billing cycles in 1994. Data on electricity consumption for each billing cycle were obtained from January 1994 through May 2002, for a total of 101 months. From these data, we calculated average daily electricity consumption by month for each household in the survey sample. ${ }^{17}$ The last row of Table 1 reports descriptive statistics for this variable $(k W h D a y)$ for participants, waitlisters, and nonparticipants. While the means for all three groups fall between 16 and 18 kilowatt-hours per day (kWh/day), nonparticipants consume significantly more electricity than participants.

The TCL\&P data also includes monthly information on residential rate schedules for each household. The basic residential rate is an increasing block-rate schedule. ${ }^{18}$ Four adjustments to this basic rate are then possible. The senior citizen rate (Senior) charges block rates that start lower

\footnotetext{
${ }^{16}$ Surveys were addressed specifically to the household member whose name appeared on monthly billing statements for electricity. The fact that Traverse City is somewhat of a retirement community is reflected in the relatively high mean age.

${ }^{17}$ Characterizing electricity consumption in this way accounts for the different number of billing days within billing cycles.

${ }^{18}$ This rate charges $6.33 \phi / \mathrm{kWh}$ for the first $16 \mathrm{kWh} /$ day, $7.31 \phi / \mathrm{kWh}$ for the next $17 \mathrm{kWh} /$ day, and $8.2 \phi / \mathrm{kWh}$ for all consumption over $33 \mathrm{kWh} /$ day.
} 
Table 1: Summary statistics for participants, nonparticipants, and waitlisters

\begin{tabular}{|c|c|c|c|c|c|c|}
\hline & (1) & (2) & (3) & (4) & (5) & (6) \\
\hline Variable & $\begin{array}{r}\text { Particip. } \\
N=106\end{array}$ & $\begin{array}{c}\text { Waitlist } \\
N=27\end{array}$ & $\begin{array}{c}\text { Nonparticip. } \\
\qquad N=544\end{array}$ & $\begin{array}{c}t \text { stat. } \\
(1) \text { vs (2) }\end{array}$ & $\begin{array}{c}t \text { stat. } \\
(1) \text { vs }(3)\end{array}$ & $\begin{array}{c}t \text { stat. } \\
(2) \text { vs }(3)\end{array}$ \\
\hline Income & $\begin{array}{c}66.064 \\
(37.163)\end{array}$ & $\begin{array}{c}68.462 \\
(29.488)\end{array}$ & $\begin{array}{c}56.949 \\
(34.611)\end{array}$ & 0.303 & $2.302^{* *}$ & $1.663^{*}$ \\
\hline FamSize & $\begin{array}{c}2.340 \\
(1.193)\end{array}$ & $\begin{array}{c}2.154 \\
(0.834)\end{array}$ & $\begin{array}{c}2.233 \\
(1.310)\end{array}$ & 0.749 & 0.766 & 0.305 \\
\hline Own (1=yes) & 0.961 & 1.000 & 0.915 & 1.017 & 1.606 & 1.552 \\
\hline House (1=yes) & 0.876 & 0.923 & 0.867 & 0.668 & 0.243 & 0.823 \\
\hline AptCondo (1=yes) & 0.105 & 0.077 & 0.104 & 0.422 & 0.018 & 0.446 \\
\hline MobHome (1=yes) & 0.019 & 0.000 & 0.028 & 0.705 & 0.541 & 0.870 \\
\hline Age & $\begin{array}{c}56.324 \\
(13.976)\end{array}$ & $\begin{array}{c}55.462 \\
(12.465)\end{array}$ & $\begin{array}{c}60.504 \\
(14.874)\end{array}$ & 0.287 & $2.618^{* * *}$ & $1.698^{*}$ \\
\hline Gender $(1=$ male $)$ & 0.500 & 0.577 & 0.525 & 0.697 & 0.462 & 0.517 \\
\hline Education & $\begin{array}{l}16.349 \\
(3.01)\end{array}$ & $\begin{array}{l}16.444 \\
(2.778)\end{array}$ & $\begin{array}{l}14.528 \\
(2.802)\end{array}$ & 0.149 & $6.028^{* * *}$ & $3.467^{* * *}$ \\
\hline Conserv $(1=$ yes $)$ & 0.471 & 0.444 & 0.158 & 0.240 & $7.367^{* * *}$ & $2.883^{* * *}$ \\
\hline$k W h D a y$ & $\begin{array}{l}16.105 \\
(6.847)\end{array}$ & $\begin{array}{l}16.439 \\
(8.258)\end{array}$ & $\begin{array}{c}17.950 \\
(10.070)\end{array}$ & 0.214 & $1.806^{*}$ & 0.572 \\
\hline
\end{tabular}

Notes: Standard deviations are in parentheses and reported for continuous variables only. The number of observations for each statistic varies somewhat due to item nonresponse. Income is household pre-tax income in year 2000 measured in 1000s of dollars. FamSize indicates the number of family members living in the household. Own indicates ownership. House, AptCondo, and MobHome indicate house, apartment/condominium, or mobile home. Age, Gender, and years of Education correspond to the respondent. Conserv indicates self-reported membership in an environmental organization. $k W h D a y$ is average daily electricity consumption by month, measured in kilowatt-hours. One, two, or three asterisks indicate significance at the levels $p<0.10, p<0.05$, or $p<0.01$, respectively. 
and end higher. ${ }^{19}$ The electric water heating service (WtrHeat) allots households an additional 13 $\mathrm{kWh}$ /day at the lowest rate of their rate class. Electric space heating service (SpcHeat) charges households only the lowest rate of their rate class on all electricity consumption for the billing months of November through May. ${ }^{20}$ Finally, as described previously, the Green Rate (GrnRate) charges an additional $1.58 \phi / \mathrm{kWh}$ for all electricity consumption. The Green Rate became available starting in June 1996. All other rate schedules remained constant throughout the study period.

\subsection{Classifying Conservationists and Nonconservationists}

Testing predictions of the theoretical model requires classifying households as either conservationists or nonconservationists. While identifying underlying preferences poses an inherent empirical challenge, we use self-reported membership in an environmental organization to classify conservationists. In particular, we use the variable Conserv, which is a dummy variable based on belonging to an environmental organization other than participation in the Green Rate program. ${ }^{21}$ One advantage of this strategy is its consistency with the psychological basis of the model. Recall the underlying distinction between conservationists and nonconservationists: only conservationists are aware of environmental problems that arise through generation of conventional electricity and are willing to take personal responsibility for addressing the problems. While membership in an environmental organization is likely to apply to environmental concerns more generally, it is a reasonable indicator of knowledge about environmental problems and willingness to take personal responsibility.

But how is membership in an environmental organization related to specific preferences about conservation of electricity? This question is important for our analysis, and part of the survey was designed to provide an answer. Table 2 compares descriptive statistics for responses split by Conserv, and the results suggest that the variable is a reasonable indicator for classifying conservationists and nonconservationists with respect to electricity demand.

\footnotetext{
${ }^{19}$ This option charges increasing block rates of $5.3 \phi, 8.3 \phi$, and $9.3 \phi$.

${ }^{20}$ The sample percentages to which these rate adjustments apply are as follows: 23.7 percent for Senior, 7.3 percent for WtrHeat, and 1.6 percent for SpcHeat.

${ }^{21}$ The variable Conserv was created from a survey question that asked respondents to indicate the types of organizations to which they belonged. Response categories include community service organizations, church or religious groups, labor or trade unions, environmental organizations, and professional organizations.
} 
Table 2: Comparison of responses between conservationists and nonconservationists

\begin{tabular}{|c|c|c|c|c|c|}
\hline \multirow[t]{2}{*}{ Survey Question } & \multicolumn{2}{|c|}{$\begin{array}{l}\text { Conservationists } \\
(\text { Conserv }=1) \\
N=141\end{array}$} & \multicolumn{2}{|c|}{$\begin{array}{l}\text { Nonconservationists } \\
(\text { Conserv }=0) \\
N=502\end{array}$} & \multirow[b]{2}{*}{$t$ stat. } \\
\hline & Mean & Std. Err. & Mean & Std. Err. & \\
\hline \multicolumn{6}{|l|}{$\begin{array}{l}\text { If you could choose among electric companies, } \\
\text { which of the following characteristics of a company } \\
\text { would be important to your decision } ?^{a}\end{array}$} \\
\hline Electricity rates & 0.940 & 0.024 & 0.922 & 0.013 & 0.677 \\
\hline Reliability of electric service & 0.918 & 0.029 & 0.865 & 0.016 & 1.587 \\
\hline Environmental impacts of electricity production & 0.951 & 0.024 & 0.563 & 0.024 & $11.516^{* * *}$ \\
\hline Customer service & 0.790 & 0.044 & 0.717 & 0.022 & 1.488 \\
\hline Community involvement of company & 0.449 & 0.053 & 0.313 & 0.022 & $2.344^{* *}$ \\
\hline $\begin{array}{l}\text { When considering the purchase of a major appliance, } \\
\text { how important to you is energy efficiency compared } \\
\text { to price? }\end{array}$ & 3.304 & 0.079 & 3.138 & 0.035 & $1.931^{*}$ \\
\hline \multicolumn{6}{|l|}{$\begin{array}{l}\text { Which of the following energy-saving activities does } \\
\text { your household engage in? }\end{array}$} \\
\hline Regularly turn off lights in unused rooms & 0.937 & 0.025 & 0.962 & 0.009 & 0.929 \\
\hline Keep thermostat at a low temperature in winter & 0.792 & 0.043 & 0.702 & 0.022 & $1.876^{*}$ \\
\hline Conserve on air conditioning in summer & 0.456 & 0.052 & 0.381 & 0.023 & 1.311 \\
\hline Reduce temperature setting on water heater & 0.580 & 0.052 & 0.387 & 0.023 & $3.395^{* * *}$ \\
\hline Add insulation in home & 0.666 & 0.049 & 0.521 & 0.024 & $2.635^{* * *}$ \\
\hline Install energy-saving lights & 0.461 & 0.052 & 0.247 & 0.021 & $3.806^{* * *}$ \\
\hline $\begin{array}{l}\text { How much electricity do you think your household } \\
\text { uses compared to other households of similar size }\end{array}$ & & & & & \\
\hline and characteristics? ${ }^{b}$ & 2.474 & 0.090 & 2.674 & 0.038 & $-2.042^{* * *}$ \\
\hline
\end{tabular}

Notes: Statistics are based on weighted responses to correct for stratified sampling. Number of observations for each statistic varies somewhat due to item nonresponse. ${ }^{a}$ Responses for each item are coded as $1=$ yes and $0=$ no. ${ }^{b}$ Responses are based on a Likert scale ranging from $1=$ much less to $5=$ much more. One, two, or three asterisks indicate significance at the levels $p<0.10, p<0.05$, or $p<0.01$, respectively. 
The first set of questions listed in the table asks about what company characteristics would be important to consider if given the opportunity to choose between different electric companies. While the responses do not differ significantly with respect to electricity rates, reliability, and customer service, the responses do differ significantly with respect to the environmental impacts and community involvement, with conservationists caring more about both. Responses to the second question indicate that conservationists place significantly more importance on energy efficiency compared to price when purchasing a major appliance. Responses to the third set of questions indicate that conservationists engage in more energy-saving activities. Finally, responses to the last question indicate that conservationists perceive their own household to use less electricity than other households of similar size and characteristics. Note that this last result corresponds directly with the notion of voluntary restraint, which we test formally in the next section. Here again we conducted Mann-Whitney $U$ tests to assess whether the different groups of observations come from the same distribution, and the results for statistically significant differences were the same as those reported in Table 2 for $t$-tests.

We also compared responses to these same questions within the subsamples of only participants or nonparticipants in the Green Rate program. This approach controls for program participation and allows us to isolate differences that are due only to Conserv. The results for both participants and nonparticipants follow the same pattern as those in Table 2, so we do not report them separately. These results provide evidence that the classification as either conservationist or nonconservationist is distinct from participant or nonparticipant. In other words, "participating nonconservationists" are not misclassified conservationists, and "nonparticipating conservationists" are not misclassified nonconservationists.

In sum, the differences in responses summarized in Table 2 provide support for using membership in an environmental organization as a proxy variable to classify households as conservationists or nonconservationists with respect to electricity consumption. Interestingly, part of the analysis evaluates whether the stated preferences related to electricity consumption correspond with revealed preferences that actually affect electricity consumption. 


\section{Econometric Specification and Estimation}

The predictions of the theoretical model relate to differences in electricity consumption along two dimensions: between conservationists and nonconservationists, and before and after participation in the Green Rate program. In this section we describe our empirical strategies for testing these predictions.

We employ a difference-in-differences methodology and estimate regression models of the general form

$$
\begin{aligned}
\text { WhDay }_{i t}= & {\text { } \text { Conserv }_{i}+\alpha \text { GrnRate }_{i t}+\text { SConserv }_{i} \cdot \text { GrnRate }_{i t}} \\
& +\mathbf{X}_{i t} \boldsymbol{\beta}+\lambda_{t}+\nu_{i}+\varepsilon_{i t},
\end{aligned}
$$

where $i$ indexes households, $t$ indexes time periods, GrnRate $i t$ is a dummy variable that equals 1 when the household is participating in the Green Rate program and 0 otherwise, and $\mathbf{X}_{i t}$ is a row vector of other explanatory variables (income, the other rate-class schedules, and household characteristics).

The key parameters for testing the theoretical propositions are $\varphi, \alpha$, and $\delta$, which are interpreted as follows: $\varphi$ estimates the average difference in conventional-electricity consumption between conservationists and nonconservationists; $\alpha$ estimates nonconservationists' average change in electricity consumption after participating in the green-electricity program; and $\delta$ estimates the average difference between conservationists' and nonconservationists' change in electricity consumption after participating in the green-electricity program. Two linear combinations of these parameters are also of interest: $\alpha+\delta$ estimates conservationists' average change in electricity consumption after participating in the green-electricity program; and $\varphi+\delta$ estimates the average difference in green-electricity consumption between participating conservationists and participating nonconservationists.

The coefficients in equation (3) are estimated several ways. We first use a random effects model that includes all of the observations (participants, waitlisters, and nonparticipants). The primary advantage of the random effects model is that it enables identification of the coefficient on Conserv $_{i}$, which is a time-invariant. Yet, to ensure consistency of the random effects estimator, we need to 
assume that the unobserved effect $v_{i}$ is uncorrelated with the observed explanatory variables (see Wooldridge, 2002). To test whether this assumption is reasonable, we also estimate a fixed effects model for purposes of comparison.

The random effects estimates are reported as the Full Sample model in Table 3. Beyond the variables explicitly specified in (3), the model includes the following: household income; dummy variables for the additional rate-class schedules $\left(\right.$ Senior $_{i t}$, WtrHeat $_{i t}$, SpcHeat $_{i t}$ ); the variables listed in Table 1 that relate to sociodemographic characteristics and the physical attributes of each residence; and dummy variables to control for different months and years (not reported). ${ }^{22}$ The corresponding fixed effects estimates are reported in the Appendix. The similarity of the estimated parameters between models - especially $\hat{\alpha}$ and $\hat{\delta}$ - suggest that the random effects model is not restrictive. Moreover, a Hausman test comparing both sets of estimates fails to reject the null hypothesis that the coefficients are the same in both models. The $\chi^{2}$ test statistic is reported at the bottom of Table 3 and is not statistically significant at any reasonable level of confidence.

We report two sets of standard errors. Bertrand, Duflo, and Mullainathan (2004) demonstrate how failure to account for potential serial correlation in difference-in-differences estimation results in underestimates of the true standard errors. Here we follow their recommended solution by estimating standard errors based on block bootstraps, where we draw 200 bootstrap samples. To see the effect of this correction, we report both the conventional and block bootstrap standard errors. As expected, accounting for serial correlation generally increases the standard errors, yet the effect is not large enough to change the main results.

The inclusion of GrnRate $_{i t}$ in equation (3) is consistent with a general class of models that seek to estimate average treatment effects. In such models, potential endogeneity of the treatment must be addressed. ${ }^{23}$ The fact that we have panel data is useful in this regard; for equation (3) will produce consistent estimates provided that GrnRate $_{i t}$ is uncorrelated with time-varying unobservables that affect electricity consumption (see Wooldridge, 2002). While we believe this

\footnotetext{
${ }^{22}$ Despite the stratified sample, we estimate unweighted regression models. In cases such as ours, when stratification is based on an explanatory variable (i.e., GrnRate), the weighting of regression models is unnecessary (see Wooldridge, 2002).

${ }^{23}$ Endogeneity of Conserv $_{i}$ is not a concern because it is reasonable to assume that membership in an environmental organization (excluding participation in the Green Rate program) is exogenous to a household's choices pertaining to electricity consumption.
} 
assumption is reasonable, we further address potential endogeneity concerns. A plausible, though perhaps unlikely, scenario is that households foresee future reductions in their electricity demand and, therefore, are more likely to participate is the Green Rate program, as participation will be less costly. ${ }^{24}$

To address this concern, we estimate models using subsets of the observations and compare the results with those for the Full Sample models. One specification that we use is identical to equation (3), but includes only the participants and waitlisters; that is, nonparticipants are excluded from the estimation. As described previously, participants and waitlisters provide a natural experiment in which to test the effect of GrnRate $i$, because actual participation was effectively exogenous. With this subset of observations, we can identify all of the parameters with the exception of SpcHeat ${ }_{i t}$, which does not apply to any household in the subset. The results of the random effects estimator are reported as the Natural Experiment model in Table 3, and the results of the fixed effects estimator are reported in the Appendix. As with the Full Sample models, the Hausman test fails to reject the null hypothesis of equal coefficients at any reasonable level of confidence, and the estimated coefficients are very similar between the two models.

Another model that we estimate considers only time periods prior to the Green Rate program. This includes all observations between January 1994 and July 1996 for all three groups (participants, waitlisters, and nonparticipants). With this subset of data, we can ignore the program entirely and focus on estimating the extent of voluntary restraint, albeit over a shorter duration of time. The general form of the specification is

$$
k W h \text { Day }_{i t}=\varphi \text { Conserv }_{i}+\mathbf{X}_{i t} \boldsymbol{\beta}+\lambda_{t}+\nu_{i}+\varepsilon_{i t}
$$

which differs from equation (3) because $\alpha=\delta=0$. The random effects and fixed effects estimates of equation (4) are reported as the Before Program models, in Table 3 and the Appendix, respectively. ${ }^{25}$

\footnotetext{
${ }^{24}$ One approach for dealing with such endogeneity is to use instrumental variable techniques in a dummy endogenous variable model (Heckman, 1978), but this approach requires a good instrument for GrnRate ${ }_{i t}$, which we do not have in this case.

${ }^{25}$ In this case, comparisons between the random and fixed effects estimators are limited because so few parameters can be identified with fixed effects. We nevertheless report both sets of results in the interest of completeness.
} 
Table 3: Random effects models of household electricity consumption

\begin{tabular}{|c|c|c|c|c|c|c|}
\hline \multirow[b]{3}{*}{ Variable } & \multicolumn{2}{|r|}{ (FS) } & \multicolumn{2}{|r|}{$(\mathrm{NE})$} & \multicolumn{2}{|c|}{$(\mathrm{BP})$} \\
\hline & \multicolumn{2}{|c|}{ Full Sample } & \multicolumn{2}{|c|}{ Natural Experiment } & \multicolumn{2}{|c|}{ Before Program } \\
\hline & Coef. & Std. Err. & Coef. & Std. Err. & Coef. & Std. Err. \\
\hline \multirow[t]{2}{*}{ Conserv $(\hat{\varphi})^{\dagger}$} & -1.591 & $(0.852)^{* *}$ & -0.236 & $(1.162)$ & -1.739 & $(0.971)^{* *}$ \\
\hline & & {$[0.715]^{* *}$} & & {$[1.101]$} & & {$[0.713]^{* *}$} \\
\hline \multirow[t]{2}{*}{ GrnRate $(\hat{\alpha})^{\dagger}$} & -0.701 & $(0.208)^{* * *}$ & -1.541 & $(0.192)^{* * *}$ & - & - \\
\hline & & {$[0.518]^{*}$} & & {$[0.549]^{* * *}$} & & - \\
\hline \multirow[t]{2}{*}{ Conserv $\cdot$ GrnRate $(\hat{\delta})^{\dagger}$} & 0.560 & $(0.293)^{* *}$ & 0.623 & $(0.217)^{* * *}$ & - & - \\
\hline & & {$[0.787]$} & & {$[0.698]$} & & - \\
\hline \multirow[t]{2}{*}{ Senior } & -0.336 & $(0.337)$ & -0.427 & $(0.563)$ & -0.771 & $(1.168)$ \\
\hline & & {$[0.504]$} & & {$[0.963]$} & & {$[0.701]$} \\
\hline \multirow[t]{2}{*}{ WtrHeat } & -0.764 & $(0.567)$ & 5.288 & $(3.307)$ & 0.197 & $(1.528)$ \\
\hline & & {$[2.201]$} & & {$[2.340]^{* *}$} & & [0.953] \\
\hline \multirow[t]{2}{*}{ SpcHeat } & 6.497 & $(0.429)^{* * *}$ & - & - & 5.510 & $(0.916)^{* * *}$ \\
\hline & & {$[4.394]$} & & - & & {$[6.744]$} \\
\hline \multirow[t]{2}{*}{ Income } & 0.051 & $(0.012)^{* * *}$ & 0.034 & $(0.020)^{*}$ & 0.042 & $(0.014)^{* * *}$ \\
\hline & & {$[0.014]^{* * *}$} & & {$[0.020]^{*}$} & & {$[0.016]^{* * *}$} \\
\hline \multirow[t]{2}{*}{ FamSize } & 1.181 & $(0.173)^{* * *}$ & 2.037 & $(0.217)^{* * *}$ & 1.711 & $(0.310)^{* * *}$ \\
\hline & & {$[0.564]^{* *}$} & & {$[0.842]^{* *}$} & & {$[0.513]^{* * *}$} \\
\hline \multirow[t]{2}{*}{ Own } & 2.418 & $(1.541)$ & 0.496 & $(3.612)$ & 2.584 & $(1.864)$ \\
\hline & & {$[1.122]^{* *}$} & & {$[3.268]$} & & {$[1.358]^{*}$} \\
\hline \multirow[t]{2}{*}{ AptCondo } & -4.302 & $(1.342)^{* * *}$ & -5.908 & $(2.148)^{* * *}$ & -3.846 & $(1.569)^{* *}$ \\
\hline & & {$[0.957]^{* * *}$} & & {$[1.479]^{* * *}$} & & {$[1.064]^{* * *}$} \\
\hline \multirow[t]{2}{*}{ MobHome } & -1.909 & $(2.299)$ & 5.132 & $(4.532)$ & -0.588 & $(2.611)$ \\
\hline & & {$[1.720]$} & & {$[39.16]$} & & {$[2.421]$} \\
\hline \multirow[t]{2}{*}{ Age } & -0.019 & $(0.026)$ & 0.062 & $(0.043)$ & 0.022 & $(0.036)$ \\
\hline & & {$[0.032]$} & & {$[0.083]$} & & {$[0.024]$} \\
\hline \multirow{2}{*}{ Gender } & 1.332 & $(0.709)^{*}$ & -1.743 & $(1.255)$ & 1.521 & $(0.808)^{*}$ \\
\hline & & {$[0.564]^{* *}$} & & {$[1.214]$} & & {$[0.641]^{* *}$} \\
\hline \multirow[t]{2}{*}{ Education } & 0.154 & $(0.143)$ & 0.186 & $(0.233)$ & 0.148 & $(0.163)$ \\
\hline & & {$[0.117]$} & & {$[0.212]$} & & {$[0.114]$} \\
\hline Month dummies & & Yes & & Yes & & Yes \\
\hline Year dummies & & Yes & & Yes & & Yes \\
\hline Observations & & 59,731 & & 11,875 & & 16,072 \\
\hline Households & & 637 & & 127 & & 596 \\
\hline R-squared (overall) & & 0.16 & & 0.22 & & 0.15 \\
\hline Hausman test $\chi^{2}$ & & 4.26 & & 4.76 & & 3.93 \\
\hline Predicted $\overline{k W h D a y}_{i t}$ & & 17.755 & & 16.257 & & 17.996 \\
\hline
\end{tabular}

Notes: The dependent variable is average daily electricity consumption by month, $k$ WhDayit. Conventional standard errors are in parentheses; block bootstrap standard errors are in brackets. House is the omitted category with respect to AptCondo and MobHome. Missing data for all survey variables other than Conserv were filled with the means corresponding to the household's status as a participant, waitlister, or nonparticipant. The $\dagger$ indicates significance level based on a one-tailed test. One, two, or three asterisks indicate significance at the levels $p<0.10, p<0.05$, or $p<0.01$, respectively. 


\section{$5 \quad$ Empirical Results}

Our discussion of the results focuses on the random effects models because they allow identification of all parameters of interest, and they generate results that are very similar to those for the fixed effects models. The Full Sample, Natural Experiment, and Before Program models are referred to hereafter as the FS, NE, and BP models, respectively.

Voluntary Restraint. Proposition 1 predicts that conservationists will consume less conventional electricity than nonconservationists. The estimate of $\varphi$ in the FS model supports this prediction; it is negative and statistically significant, indicating that conservationists consume less conventional electricity. The magnitude of this difference is $-1.591 \mathrm{kWh} /$ day on average, which is a 9-percent reduction from the predicted level of average household consumption. With the FS model, therefore, we find evidence of substantial voluntary restraint: controlling for observed and unobserved heterogeneity, conservationists consume an average of 9 percent less conventional electricity.

The same result does not emerge in the NE model. While the estimate of $\varphi$ is negative, it is not statistically different from zero. One reason for the difference may be the fact that electricity demand for participants and waitlisters is very close to the threshold (of $16 \mathrm{kWh} /$ day) between the first and second block rates, whereas this is not the case for nonparticipants (see Table 1). ${ }^{26}$ In such cases - where demand is exactly at the threshold between block rates - we have shown previously that the theory does not predict differences in consumption between conservationists and nonconservationists. Other possible reasons for the insignificance of voluntary restraint in the NE model include the facts that the number of observations is substantially lower, and that there is less variation in Conserv $_{i}$ when nonparticipants are excluded. For all of these reasons, we argue that the NE model does not generate the most reliable estimate of voluntary restraint.

The BP model provides a better alternative to compare with the FS model. While the panels in the BP model are limited to observations prior to July 1996, there is greater cross-sectional variation, as participants, waitlisters, and nonparticipants are all included. The estimate of $\varphi$ in the BP model is -1.739 , and it is statistically different from zero, suggesting again that conservationists consume less conventional electricity. The difference is an average of $1.739 \mathrm{kWh} /$ day,

\footnotetext{
${ }^{26}$ This reduces the predicted level of average household consumption from approximately $17.8 \mathrm{kWh} /$ day in the FS model to approximately $16.3 \mathrm{kWh} /$ day in the $\mathrm{NE}$ model.
} 
which translates into a 9.6-percent reduction from the model's predicted level of average household consumption. This result is very similar to that for the FS model and thereby provides further evidence of substantial voluntary restraint.

It is always possible that the results for voluntary restraint are subject to omitted variable bias, whereby we are missing time-invariant variables that are correlated with both Conserv $_{i}$ and electricty consumption. Possibilities may include spending time outdoors or watching less television. But many other possibilities, such as living in a smaller house or having more energy efficient appliances, would not a pose a problem for the analysis, as they may only reflect the mechanism by which conservationists affect their electricity consumption. ${ }^{27}$

Nonconservationists. The first part of Proposition 2 shows that nonconservationists will participate in the Green Rate program only if they derive a sufficiently large lump-sum benefit. The fact that many households without membership in an environmental organization actually participated is suggestive of this benefit. The second part of Proposition 2 enables a more sophisticated test, however. The prediction is that participating nonconservationists will reduce their electricity consumption, and the magnitude of their reduction will be as if there had been an increase in the price of conventional electricity equal to the green-electricity premium. The estimates of $\alpha$ test this prediction. In both the FS and NE models, the estimated coefficient is negative and statistically significant, indicating that participating nonconservationists do in fact reduce their electricity consumption. The average magnitude of this reduction is 0.701 and $1.541 \mathrm{kWh} /$ day, or 3.9 and 9.5 percent from the predicted means, for the FS and NE models, respectively. ${ }^{28}$

But how do these estimates for reduced electricity consumption compare to what would have occurred with only an increase in the price of conventional electricity equal to the premium of $1.58 \% / \mathrm{kWh}$ ? To answer this question, we derive price elasticities based on the voluntary premium and compare them to previously published estimates of the price elasticity for conventional electric-

\footnotetext{
${ }^{27}$ We did ask a survey question about square footage of the residence, but we find no statistically significant difference between conservationists and nonconservationists. When we include the variable in the regression models, it only strengthens the results, both in magnitude and statistical significance. We do not include the variable in the reported models because of a relatively high degree of nonresponse ( 22 percent).

${ }^{28}$ Recall the potential endogeneity issue regarding GrnRate $_{i t}$ in the FS model. If this were indeed a problem, we would expect $\hat{\alpha}$ to overestimate the true effect. The fact that $\hat{\alpha}$ in the NE model is even larger lends support to the argument that endogeneity in the FS model is not a concern.
} 
ity. We calculate the elasticities using the percentage change in the average price. ${ }^{29}$ Our estimates of the voluntary-price elasticity are -0.16 for the FS model and -0.38 for the NE model.

It turns out that both estimates of the voluntary-price elasticity are well within the range of the price elasticities for conventional electricity that are reported in the literature, which generally fall between -0.1 and -0.7 (see Bohi and Zimmerman, 1984, and Berndt, 1991). We therefore cannot reject the hypothesis that participating nonconservationists respond as if there had only been an increase in the price of conventional electricity. Recall that, in the context of the theoretical model, this result implies that participation is motivated by a lump-sum benefit, due possibly to the social and psychological benefits described earlier.

Conservationists. What happens to the electricity consumption of participating conservationists? The first part of Proposition 3 identifies the possibility for an increase, a decrease, or no change in electricity consumption. Here the econometric results provide evidence of no change in consumption. The average change in consumption for a participating conservationist is given by the linear combination of $\alpha+\delta$ in specification (3). Estimates of this linear combination are -0.141 and $-0.918 \mathrm{kWh} /$ day for the FS and NE models, respectively. While both estimates of the linear combination are negative, neither is statistically different from zero. ${ }^{30}$ Thus, conservationists - who were already exhibiting voluntary restraint - exhibit no statistically significant change in consumption after participating in the Green Rate program. In the context of the theoretical model, this implies that the price premium for green electricity is approximately equal to the subjective externality that conservationists were voluntarily internalizing with conventional electricity. It is possible, however, that the result also reflects greater inelasticity of demand for conservationists, as they are already exhibiting voluntary restraint.

Conservationists versus nonconservationists. Proposition 4 makes two predictions about the relationship between conservationists and nonconservationists. The first prediction is that participating conservationists will reduce their electricity consumption by (weakly) less than participating nonconservationists. This prediction is consistent with a positive coefficient $\delta$ on the interaction

\footnotetext{
${ }^{29}$ This approach provides a straightforward way to account for the block-rate pricing and is consistent with much of the literature on estimating electricity demand. See Bohi and Zimmerman (1984) for a discussion and literature review.

${ }^{30}$ Wald tests, using either set of standard errors, fail to reject the null hypothesis that $\alpha+\delta=0$.
} 
term Conserv.GrnRate. In both the FS and NE models, the coefficient is positive and approximately equal to 0.6 . While both estimates are statistically significant with the conventional standard errors, accounting for potential serial correlation renders them both statistically insignificant.

The second prediction of Proposition 4 is that, after controlling for other factors, conservationists and nonconservationists who participate in the Green Rate program will consume the same amount of green electricity. We test this prediction with the hypothesis that $\varphi+\delta=0$. Estimates of this linear combination are -1.031 and $0.387 \mathrm{kWh} /$ day for the FS and NE models, yet Wald tests reveal that neither estimate is statistically different from zero. Thus, the two types of households are indistinguishable with respect to green-electricity consumption. According to the theoretical model, this similarity occurs because conservationists have no reason to voluntarily restrain their consumption of green electricity, as it generates no pollution.

Other determinants of electricity consumption. The remaining coefficients in Table 3 provide information about other factors that influence electricity consumption. There is evidence that electric heating affects consumption in the expected way. Based on the FS and BP models, the coefficient on SpcHeat is positive, indicating that, in the months when heating is required, the households with electric heat use more electricity than households without it. This effect is not statistically significant, however, after accounting for serial correlation. Households with higher income consume significantly more electricity, and the implied income elasticities are $0.16,0.13$, and 0.13 in the FS, NE, and BP models. ${ }^{31}$ The number of family members living in the household has a positive and significant effect on electricity consumption. Electricity consumption is significantly lower in apartments and condominiums compared to houses; whereas, mobile homes are not significantly different from houses. Home ownership does not have a significant effect on electricity consumption, nor do the sociodemographic characteristics of age and education. Gender does have a significant effect in the FS and BP models, and the positive coefficient indicates that a female name on billing statements is associated with lower electricity consumption. Although not reported, the year dummies exhibit no general trend, while the month dummies indicate more electricity consumption during the winter months. This latter result is to be expected in places

\footnotetext{
${ }^{31}$ These elasticity estimates are within the range of income elasticities reported in the literature for electricity demand (see Bohi and Zimmerman, 1984, and Berndt, 1991).
} 
like Traverse City, where the number of daylight hours is substantially lower in the winter, and air conditioning is not common in the summer.

\section{Summary and Conclusion}

This paper investigates how concern for the environment translates into predictable patterns of behavior. Three questions provide the focus of analysis: Do preferences for environmental quality result in the voluntary restraint of consumption? What explains willingness to pay a premium for environmentally friendly goods and services? And what is the relationship between voluntary restraint and voluntary price premiums?

The theoretical model starts with the distinction between conservationists and nonconservationists. Only conservationists care about environmental quality in a way that promotes concern about the effects of their consumption decisions on the environment. This concern-motivated perhaps by guilt alone - translates into the voluntary restraint of consumption. While voluntary restraint is conservation based on the choice of quantities, the model also considers conservation based on the choice of prices. When the opportunities are available, the desire to avoid generating pollution may translate into payment of a voluntary premium for substitute goods and services that are more environmentally friendly. These different mechanisms for voluntary conservation mirror the relationship between traditional environmental policies based on quantities or prices.

An additional feature of the model is that willingness to pay a voluntary price premium is motivated by more than just the desire to reduce pollution. Social and psychological benefits play a role. These benefits may be related to social approval, prestige, and warm glow - the same motives that have been shown to motivate private provision of public goods. For both conservationists and nonconservationists, these motives are captured with a potential lump-sum benefit. According to the model, therefore, both conservationists and nonconservationists may be willing to pay a voluntary price premium, whereas only conservationists exhibit voluntary restraint.

The empirical portion of the paper analyzes household electricity demand before and after introduction of a green-electricity program. The analysis takes advantage of original survey data

and utility data to estimate differences in electricity consumption between conservationists and 
nonconservationists, before and after participation in the green-electricity program. The empirical setting provides a unique natural experiment in which program participants are compared to a control group of households on the program's waiting list.

The empirical results are consistent with the theoretical predictions. There is evidence of substantial voluntary restraint, as conservationists consume almost 10 percent less conventional electricity than nonconservationists. Conservationists are also more likely to participate in the green-electricity program. Other results are based on changes in electricity consumption after paying the voluntary price premium for green electricity. Nonconservationists are found to reduce their consumption after participating in the program. In particular, they reduce consumption as if there had been an increase in the price of conventional electricity equal to the premium for green electricity. In the context of the model, this result is consistent with the existence of social and psychological benefits of the green-electricity program that are unrelated to electricity consumption. In contrast, conservationists, who were already exhibiting voluntary restraint, do not reduce their electricity consumption after paying the price premium for green electricity. This result is consistent with the price premium for green electricity being approximately equal to the subjective externality that conservationists were voluntarily internalizing with conventional electricity. Finally, there is evidence that conservationists and nonconservationists are indistinguishable with respect to consumption of green electricity. The theory underlying this result is that voluntary restraint does not apply to environmentally friendly goods and services.

To conclude, the theoretical analysis provides new insight into the economics of voluntary conservation. Understanding behavior of this type is important, as it opens the door to consideration of the potential ways in which voluntary conservation can serve as a complement or substitute for more centralized forms of energy and environmental policy. The theoretical model generates a series of novel predictions about the relationship between voluntary restraint and voluntary price premiums. We find empirical support for all of the theoretical predictions. It is worth noting that the preceding analysis has been entirely positive rather than normative. While the focus has been on explaining and predicting behavior, we have not addressed the question of whether the green electricity program is socially beneficial. Benefits certainly accrue to participants, and the public also benefits from any emission reductions. But green electricity programs, including the one 
studied here, are often subsidized. Whether the social benefits exceed the costs in green electricity programs is a question for future research. Moreover, future research should investigate whether the behavioral findings here are robust to consumption of different goods and services. Opportunities for such research are increasingly available, as markets for environmentally friendly goods and services continue to expand. 
Appendix Table: Fixed effects models of household electricity consumption

\begin{tabular}{|c|c|c|c|c|c|c|}
\hline \multirow[b]{2}{*}{ Variable } & \multicolumn{2}{|r|}{$(\mathrm{FS})$} & \multicolumn{2}{|r|}{$(\mathrm{NE})$} & \multicolumn{2}{|c|}{$\begin{array}{c}\text { (BP) } \\
\text { Before Program }\end{array}$} \\
\hline & Coef. & Std. Err. & Coef. & Std. Err. & Coef. & Std. Err. \\
\hline \multirow[t]{2}{*}{ Conserv $(\hat{\varphi})^{\dagger}$} & - & - & - & - & - & - \\
\hline & & - & & - & & - \\
\hline \multirow[t]{2}{*}{$\operatorname{GrnRate}(\hat{\alpha})^{\dagger}$} & -0.610 & $(0.210)^{* * *}$ & -1.519 & $(0.193)^{* * *}$ & - & - \\
\hline & & {$[0.518]$} & & {$[0.615]^{* *}$} & & - \\
\hline \multirow[t]{2}{*}{ Conserv $\cdot$ GrnRate $(\hat{\delta})^{\dagger}$} & 0.494 & $(0.296)^{* *}$ & 0.609 & $(0.218)^{* * *}$ & - & - \\
\hline & & {$[0.750]$} & & {$[0.785]$} & & - \\
\hline \multirow[t]{2}{*}{ Senior } & -0.286 & $(0.356)$ & -0.693 & $(0.587)$ & - & - \\
\hline & & {$[0.515]$} & & {$[0.927]$} & & - \\
\hline \multirow[t]{2}{*}{ WtrHeat } & -1.024 & $(0.620)^{*}$ & - & - & - & - \\
\hline & & {$[2.814]$} & & - & & - \\
\hline \multirow[t]{2}{*}{ SpcHeat } & 6.369 & $(0.430)^{* * *}$ & - & - & 5.264 & $(0.927)^{* * *}$ \\
\hline & & {$[4.530]$} & & - & & {$[7.048]$} \\
\hline \multirow[t]{2}{*}{ Income } & - & - & - & - & - & - \\
\hline & & - & & - & & - \\
\hline \multirow[t]{2}{*}{ FamSize } & 0.768 & $(0.207)^{* * *}$ & 1.947 & $(0.233)^{* * *}$ & 1.781 & $(0.623)^{* * *}$ \\
\hline & & {$[0.659]$} & & {$[0.963]^{* *}$} & & {$[1.356]$} \\
\hline \multirow[t]{2}{*}{ Own } & - & - & - & - & - & - \\
\hline & & - & & - & & - \\
\hline \multirow[t]{2}{*}{ AptCondo } & - & - & - & - & - & - \\
\hline & & - & & - & & - \\
\hline \multirow[t]{2}{*}{ MobHome } & - & - & - & - & - & - \\
\hline & & - & & - & & - \\
\hline \multirow[t]{2}{*}{ Age } & 0.057 & $(0.120)$ & 0.045 & $(0.138)$ & -0.174 & $(0.678)$ \\
\hline & & {$[0.293]$} & & {$[0.517]$} & & {$[0.530]$} \\
\hline \multirow[t]{2}{*}{ Gender } & - & - & - & - & - & - \\
\hline & & - & & - & & - \\
\hline \multirow[t]{2}{*}{ Education } & - & - & - & - & - & - \\
\hline & & - & & - & & - \\
\hline Month dummies & & Yes & & Yes & & Yes \\
\hline Year dummies & & Yes & & Yes & & Yes \\
\hline Observations & & 59,731 & & 11,875 & & 16,072 \\
\hline R-squared (overall) & & 0.06 & & 0.15 & & 0.07 \\
\hline Households & & 637 & & 127 & & 596 \\
\hline
\end{tabular}

Notes: The dependent variable is average daily electricity consumption by month, $k$ WhDayit. Conventional standard errors are in parentheses; block bootstrap standard errors are in brackets. House is the omitted category with respect to AptCondo and MobHome. Missing data for all survey variables other than Conserv were filled with the means corresponding to the household's status as a participant, waitlister, or nonparticipant. The $\dagger$ indicates significance level based on a one-tailed test. One, two, or three asterisks indicate significance at the levels $p<0.10, p<0.05$, or $p<0.01$, respectively. 


\section{References}

Andreoni, James, "Impure Altruism and Donations to Public Goods: A Theory of Warm-Glow Giving," Economic Journal, 100, June 1990, pp. 464-77.

Berndt, Ernst R., The Practice of Econometrics: Classic and Contemporary. Reading, MA: Addison-Wesley, 1991.

Bertrand, Marianne, Ester Duflo, and Sendhil Mullainathan, "How Much Should We Trust Differences-In-Differences Estimates?" The Quarterly Journal of Economics, 119, February 2004, pp. 249-75.

Black, J. Stanley, Paul C. Stern, and Julie T. Elworth, "Personal and Contextual Influences on Household Energy Adoptions," Journal of Applied Psychology, 70, 1985, pp. 2-21.

Bohi, Douglas R. and Mary Beth Zimmerman, "An Update on Econometric Studies of Energy Demand," Annual Review of Energy, 9, 1984, pp. 105-54.

Champ, Patricia A. and Richard C. Bishop, "Donation Payment Mechanisms and Contingent Valuation: An Empirical Study of Hypothetical Bias," Environmental and Resource Economics, 19, 2001, pp. 338-402.

Dillman, Donald, Mail and Telephone Surveys. New York: Wiley and Sons, 1978.

Glazer, Amihai and Kai A. Konrad, "A Signalling Explanation for Charity," American Economic Review, 86, September 1986, pp. 1019-28.

Goett, Andrew A., Kathleen Hudson and Kenneth E. Train, "Customers' Choice among Retail Energy Suppliers: The Willingness-to-Pay for Service Attribute," Energy Journal, 21, 2000, pp. $1-28$.

Harbaugh, William T., "The Prestige Motive For Making Charitable Transfers," American Economic Review, 88, May 1998a, pp. 277-82.

Harbaugh, William T., "What Do Donations Buy? A Model of Philanthropy Based on Prestige and Warm Glow," Journal of Public Economics, 67, February 1998b, pp. 269-84.

Heckman, James J., "Dummy Endogenous Variables in a Simultaneous Equations System," Econometrica, 46, July 1978, pp. 931-960.

Hollander, Heinz, "A Social Exchange Approach to Voluntary Cooperation," American Economic Review, 80, December 1990, pp. 1157-67.

Kahneman, Daniel and Jack L. Knetsch, "Valuing Public Goods: The Purchase of Moral Satisfaction," Journal of Environmental Economics and Management, 22, January 1992, pp. 57-70.

Kotchen, Matthew J. and Michael R. Moore, "Private Provision of Environmental Public Goods: Household Participation in Green-Electricity Programs," Journal of Environmental Economics and Management, 23, January 2007, pp. 1-16.

Lee, Albert Yin-Po, "Voluntary Conservation and Electricity Peak Demand: A Case Study of the Modesto Irrigation District," Land Economics, 57, August 1981, pp. 436-47. 
Oberholzer-Gee, Felix, "Your Contribution Counts! An Empirical Analysis of the Decision to Support Solar Energy," in Environmental Voluntary Contracts: Comparative Approaches to Regulation Innovation in the United States and Europe, Eric W. Orts and Kurt Deketelaere (Eds.), London: Kluwer Law International, 2001, pp. 425-34.

Peck, Anne. E. and O. C. Doering III, "Voluntarism and Price Response: Consumer Reaction to the Energy Shortage," Bell Journal of Economics, 7, Spring 1976, pp. 287-92.

Rege, Mari and Kjetil Telle, "The Impact of Social Approval and Framing On Cooperation in Public Good Situations," Journal of Public Economics, 88, 2004, pp. 1625-1644.

Reiss, Peter C. and Matthew W. White, "What Changes Energy Consumption Habits? Prices versus Public Pressures," Working Paper, The Wharton School, University of Pennsylvania, November 2005.

Roe, Brian, Mario F. Teisl, Alan Levy and Matthew Russell, "US Consumers' Willingness to Pay for Green Electricity," Energy Policy, 29, September 2001, pp. 917-25.

Rose, Steven K., Jeremy Clark, Gregory L. Poe, Daniel Rondeau, and William D. Schulze, "The Private Provision of Public Goods: Tests of a Provision Point Mechanism for Funding Green Power Programs," Resource and Energy Economics, 24, February 2002, pp. 131-55.

Schwartz, Shalom H., "Elicitation of Moral Obligation and Self-Sacrificing Behavior," Journal of Personality and Social Psychology, 15, 1970, pp. 283-93.

Schwartz, Shalom H., "Normative Influences on Altruism," in Advances in Experimental Social Psychology, Volume 10, Leonard Berkowitz (Ed.), New York: Academic Press, 1977, pp. 22179.

Stern, Paul C., "What Psychology Knows About Energy Conservation," American Psychologist, 47, October 1992, pp. 1224-32.

Walker, James M., "Voluntary Response to Energy Conservation Appeals," Journal of Consumer Research, 7, June 1980, pp. 88-92.

Wooldridge, Jeffrey M., Econometric Analysis of Cross Section and Panel Data, Cambridge, MA: The MIT Press, 2002. 